\title{
Significados do Terceiro Setor: de uma nova prática política à despolitização da questão social
}

\author{
Lia Pinheiro Barbosa*
}

\begin{abstract}
Resumo: A literatura corrente apresenta o Terceiro Setor sob obis vieses analíticos distintos: 1. surge como uma altemativa viável à ineficiência estatal no trato da questão social; 2. emerge do projeto político neoliberal que prima pelo esvaziamento da dimensão pública do Estadb. O presente artigo é resultadb de um estudb bibliográfico e dbjetiva apresentar algumas consideraçães sobre a construção sociopolítica do Terceiro Setor, enfatizandb uma reflexão crítica, baseada na análise dos fundamentos político-sociais correntes nas últimas três décadas que exercem influência direta na configuração deste ator social. V iser se a uma discussão acadênica sobre este sujeito, tecendo uma lógica argumentativa para se pensar o papel político desempenhadb por ele no contexto político-social latino-americano.
\end{abstract}

Palavras-chave: Terceiro Setor; participação; questão social.

\section{Introdução}

Embora os vários estudos outrora empreendidos e a própria historiografia datem o surgimento do Terceiro Setor desde a década de 1960, como derivação da cultura norteamericana das ações filantrópicas, é na década de 1990 que a temática adquire maior relevância político-social, sobretudo na América Latina, despertando o interesse acadêmico e daqueles que atuam diretamente nos segmentos organizados da sociedade civil.

Isto decorre, principalmente, do próprio avanço nos processos de instauração de uma política com traços mais democráticos e de uma maior participação da sociedade civil na vida pública durante esse período. Daí uma maior reflexão em torno do 'novo' sujeito denominado Terceiro Setor.

O debate sobre o papel político-social do Terceiro Setor apresenta abordagens diferenciadas, ora ratificando a emergência de um novo

Mestre em Sociologia, Especialista em Gestão do Terceiro Setor e Professora Assistente da Faculdade de Educação de Cratéus, da Universidade Estadual do Ceará. ator social, ora confundindo-se com a ação das chamadas organizações não-governamentais.

Em meio às múltiplas formas de defini-lo, observa-se a emergência de dois vieses analíticos, porém de caráter antagônicos: 1 . o primeiro baseia-se na premissa de que o Terceiro Setor surge como uma alternativa viável à ineficiência estatal no trato da questão social; 2. a segunda análise considera que o Terceiro Setor emerge do projeto político neoliberal que prima pelo esvaziamento da dimensão pública do Estado.

Em virtude da existência de distintas análises acerca do papel político e social do Terceiro Setor, torna-se difícil desenvolver uma conceituação precisa, dando conta do lugar de ação desse segmento no interior do cenário políticosocial latino-americano.

Assim sendo, o presente artigo, fruto de leituras e férteis discussões no primeiro momento do Curso de Especialização em Gestão do Terceiro Setor, ${ }^{1}$ objetiva apresentar algumas con-

\footnotetext{
1. Ministrado pela Universidade de Fortaleza. As leituras e as reflexões são fruto da conjugação de três disciplinas, a saber: 1. Globalização, Novas Relações de Trabalho e Novos Movimentos Sociais; 2. Estado, Sociedade e Terceiro Setor, e 3. Organizações do Terceiro Setor.
} 
siderações acerca da construção sociopolítica do Terceiro Setor, dando maior ênfase a uma reflexão crítica dedicada a estabelecer uma análise mais pormenorizada dos fundamentos político-sociais correntes nas últimas três décadas e que exercem, portanto, influência direta na configuração do chamado Terceiro Setor.

Embora se apresente, nas próximas linhas, uma percepção crítica da 'prática política' do Terceiro Setor, não se desconsidera a importância dos percursos da abordagem clássica que perpassa os vários estudos existentes sobre a origem e a atuação do Terceiro Setor nos Estados Unidos e na América Latina.

Assim, objetiva-se um diálogo com essas duas correntes analíticas. Longe de esgotar uma análise das principais questões norteadoras da ação político-social do Terceiro Setor, demonstrar-se-á a tessitura de uma lógica argumentativa fundamental para pensar o papel político desempenhado pelo Terceiro Setor no contexto político-social latino-americano.

\section{Compreendendo o conceito de Terceiro Setor}

O termo Terceiro Setor apresenta-se como um conceito em evidência, sobretudo na década de 1990, encontrando-se inserido em importantes pautas de discussões teóricas, no âmbito dos discursos acadêmico e político-social.

Terceiro Setor é uma expressão ainda pouco utilizada no Brasil. Constitui um termo traduzido do inglês - "Third Sector" - e está presente no vocabulário sociológico dos Estados Unidos, fazendo referência às doações pessoais às causas sociais, sobretudo através da participação pessoal, que se traduz por tempo de dedicação às atividades filantrópicas.

Mas o que significa, de fato, o Terceiro Setor? Conforme o pensamento clássico (Fernandes, 1994), compõe-se por organizações sem fins lucrativos, criadas e mantidas pela ênfase na participação voluntária, em âmbito nãogovernamental. No interior de suas ações, dão continuidade às práticas tradicionais de caridade, de filantropia e mecenato, dando expansão ao seu sentido graças ao conceito de cidadania por elas incorporado e de suas múltiplas manifestações na sociedade civil.
Suas atividades distinguem-se claramente das do Primeiro Setor - governo -, responsável pelas tarefas peculiares à esfera pública, e do Segundo Setor - mercado -, representado por atividades com fins lucrativos. Portanto, abrange as demais atividades que nem se submetem à lógica privada do lucro nem ao controle direto do governo.

Na década de 1980, o Terceiro Setor era articulado pelas ONGs, ${ }^{2}$ através de projetos apoiados em recursos financeiros da iniciativa privada, da cooperação internacional e, mesmo, contribuições governamentais. Em nossos dias, suas ações assumem âmbitos mais abrangentes:

[...] inclui instituições filantrópicas dedicadas à prestação de serviços nas áreas da saúde, educação, bem-estar social e de defesa dos direitos humanos, dos índios, negros e do meio ambiente, etc., criando horizontes de maior visibilidade para o exercício da participação cidadã. Constituindo um espaço para a realização de trabalhos em que indivíduos e empresas efetivam sua sensibilidade e compromissos sociais, mediante a doação de recursos financeiros, trabalho, tempo e talento às causas sociais. (Melo, 1999)

Considerando que a meta principal do Terceiro Setor é atender às demandas da sociedade atual, através do enfrentamento de numerosos e novos desafios, suas entidades sociais, dentre elas as $\mathrm{ONGs},{ }^{3}$ deverão apresentar os seguinte pré-requisitos:

2. O termo organização não-governamental surgiu pela primeira vez em 1945, em documento das Nações Unidas (ONU), designando um universo amplo de entidades que se auto-reconhecem como distintas do Estado e das instâncias governamentais e que recebem ajuda para a execução de projetos voltados para o interesse de grupos ou comunidades. Nascendo no circuito da cooperação internacional entre países da Europa Ocidental e do Terceiro Mundo, vem incorporando, nas últimas décadas, uma denominação específica de Terceiro Setor, canalizando recursos da ajuda internacional para projetos de promoção social.

3. Vale destacar que algumas ONGs discordam de sua inclusão no chamado Terceiro Setor, sobretudo por compor-se de uma diversidade de organizações, inclusive oriundas da iniciativa privada. A própria discussão em torno da formação de uma entidade de representação nacional das ONGs expressava o anseio em manter uma identidade e, principalmente, uma posição autônoma diante do Estado e do mercado. Daí, em 10 de agosto de 1991, constituir-se a Associação Brasileira de ONGs (Abong), cujo objetivo era representar a identidade das ONGs com tradição na luta pela 
Serem empreendedoras e inovadoras nos seus serviços; apresentarem flexibilidade e agilidade frente às mudanças; estabelecerem parcerias inovadoras para que possam ampliar sua independência; promoverem a capacitação de seu público alvo e de seu quadro de pessoal; serem competentes naquilo que realizam, buscarem formas de geração de renda para sobrevivência no mercado; terem identidade própria; estabelecerem uma nova relação com o Estado ao nível de parceria. (Filomeno, 1997)

Embora os registros históricos datem as origens das ONGs no Brasil na década de 1960, sua visibilidade política expressa-se, fundamentalmente, nos anos 70, momento de articulação de múltiplos atores da sociedade civil em prol da luta por um espaço público democrático e pelo pleno exercício da cidadania.

Assim sendo, na busca pela consolidação da democracia política em nosso país, as ONGs evoluem de uma ação basicamente assistencial, assumindo, gradativamente, um caráter político, no sentido de promoção de um empowerment dos segmentos sociais excluídos.

Para tanto, unem-se aos movimentos sociais rumo à articulação política de amplos setores organizados da sociedade civil para o enfrentamento do Estado militarizado e repressor. Isto porque passam a compreendê-lo como um adversário político, que deve ser enfrentado e democratizado. ${ }^{4}$

Neste sentido, a emergência das ONGs, sobretudo nos anos 70 e 80, é reconhecida como um espaço de compromisso e luta rumo à equidade e à justiça social, valorizando as potencialidades humanas e conscientizando sobre a importância de transformar-se em sujeito político, construtor e executor de práticas democráticas e cidadãs.

democratização política do país e de uma ação voltada aos segmentos populares. Para uma maior reflexão acerca da ação política e social das ONGs, ver: DANZIATO, Octávia de Carvalho Martim. ONGs e a prática social com adolescentes. Ijuí: Ed. Unijuí, 1998, e GOHN, Maria da Glória. Os sem-terra, ONGs e cidadania. São Paulo: Cortez, 1997.

4. Para uma análise pormenorizada, ver FERNANDES, Rubem César. Privado porém público: o terceiro setor na América Latina. Rio de Janeiro: Relume Dumará, 1994, p. 65-85, e DANZIATO, Octávia de Carvalho Martins. ONGs e a prática social com adolescentes: demarcações históricas e discursivas. Ijuí: Ed. Unijuí, 1998, p. 101-129.
O caráter educativo está presente nas diferentes ONGs e, para tanto, são desenvolvidas várias metodologias que buscam exercitar uma "pedagogia política"5 que fomente uma ação participativa e cidadã.

Ao longo da década de 1990, as ONGs passam a compartilhar seu espaço de atuação com outras entidades de representação da sociedade civil, compondo o que se denomina Terceiro Setor.

Dentre o construto analítico clássico da ação do Terceiro Setor na América Latina, encontramos alguns autores que sustentam a tese de que a sua emergência decorre de uma baixa atuação política dos segmentos sociais latinoamericanos e de um constante esvaziamento da dimensão pública do Estado. É o caso de Bernardo Toro (2000), o qual propõe três importantes funções para o Terceiro Setor, quais sejam: 1. construção de um projeto de nação, sobretudo em sociedades de baixa participação política; 2. ampliação da democracia por meio da formação e do fortalecimento de uma cultura cidadã e democrática entre os indivíduos; 3 . reinstitucionalização da dimensão pública da sociedade, visando ao aumento da igualdade e ao fortalecimento da governabilidade; 4 . contribuição para a viabilização de uma democracia cultural, fortalecendo a identidade e a igual participação dos diferentes símbolos e sentidos da diversidade social.

Por esse viés analítico, observamos a importância do Terceiro Setor na formação de uma 'paidéia política'. Há a compreensão de

\footnotetext{
5. Conforme pesquisa realizada por Landim, as ONGs existentes no Brasil têm uma hierarquia de suas atividades, as quais seguem a seguinte classificação: a) ONGs que trabalham segundo uma atividade principal, e b) ONGs que delimitam sua ação em cinco principais atividades. A pesquisa tinha como objetivo principal a elaboração de um catálogo de ONGs nacional. No entanto, objetivou-se também a coleta de dados que contribuísse para a compreensão da história das ONGs no Brasil. As ONGs selecionadas são de todo o Brasil e fazem parte do catálogo da Abong. No entanto, a autora menciona que nem todas as pesquisadas responderam ao questionário enviado. Ainda de acordo com os dados da pesquisa de Landim, a assessoria vem sendo uma atividade marcante dessa prática educativa. Através do apoio e de serviços prestados a um público exterior, ocorre o estabelecimento de relações de cumplicidade mútua, entre assessor e assessorado, tendo como elo de ligação a confiança e objetivos comuns. Ver LANDIM, Leilah \& COTRIM, Lectícia Ligneul. ONGs: Um Perfil - Cadastro das filiadas à Associação Brasileira de ONGs (Abong). São Paulo: Abong/Iser, 1996.
} 
diferentes formas de atuação do Terceiro Setor na esfera social, contribuindo diretamente na construção de um projeto político amplo, de valorização e legitimação de práticas verdadeiramente democráticas, autônomas e de autogestão. Reforça-se a idéia de restituição do âmbito público à medida que se busca incentivar a inserção da sociedade civil nas principais discussões político-sociais empreendidas com o Estado.

Uma outra corrente analítica compreende o Terceiro Setor por três parâmetros distintos e fundamentais: o Terceiro Setor como idéia; o Terceiro Setor como realidade, e o Terceiro Setor como ideologia (Salamon, 1997).

A primeira categoria, a saber, o Terceiro Setor como idéia, refere-se ao conjunto de valores herdados da tradição religiosa, da moral e de uma concepção mais humanitária do homem, fortalecendo o espírito altruísta, a sensibilidade e a compaixão entre os indivíduos. A confluência desses sentimentos conduz os indivíduos a uma ação em prol da aquisição de direitos, da luta pela inserção social e política, primando por uma ressignificação do próprio conceito de cidadania.

Como realidade, o Terceiro Setor representa um grande potencial econômico, sobretudo na absorção profissional e na geração de empregos. Ademais, têm uma dimensão política e uma formação variada refletida no conjunto de suas ações sociais e de seu posicionamento perante a organização político-econômica.

Por fim, Salamon apresenta o Terceiro Setor como ideologia. Nesta abordagem, o autor considera a existência de um processo de mitologização ${ }^{6}$ da ação voltada ao social, transmutada no 'mito da insignificância ou incompetência', 'mito do voluntarismo', 'mito da virtude pura'" e o 'mito da imaculada conceição'. ${ }^{10}$

\footnotetext{
6. Para o autor, o processo de mitologização funciona como um instrumento de desvalorização do papel político do Terceiro Setor, atribuindo-lhe um caráter meramente amadorístico no trato da questão social.

7. Considera o Terceiro Setor como um segmento amadorístico, que busca solapar a autoridade governamental legítima.

8. Que se apóiam basicamente na ação voluntária não-remunerada e na caridade privada.

9. A natureza de suas ações é de caráter essencialmente público, responsabilizando-se pelos segmentos necessitados.

10. As instituições do Terceiro Setor não são de origem eminentemente americana, mas de várias sociedades, derivando de ações de caridade e altruísmo.
}

Toda esta definição inicial conferida ao Terceiro Setor torna-se objeto discutível para uma segunda corrente de estudiosos, ${ }^{11}$ dos quais se compartilham, no presente artigo, algumas reflexões e teses.

Para esses pensadores, a primeira grande dificuldade existente na análise do Terceiro Setor é a reconstrução histórica do seu nascimento. Isto porque a definição desse segmento suscita a referência a outros dois setores - Estado e mercado - de igual importância para a atual configuração do cenário político-econômico. Ademais, a ação empreendida pelo Terceiro Setor confunde-se com a própria ação política das ONGs.

Assim sendo, uma das principais problemáticas recorrentes nas análises existentes é justamente o caráter intermediário conferido ao Terceiro Setor. Em outras palavras, nasce, entre um setor público estatal e um privado-lucrativo empresarial, um terceiro sujeito, de caráter privado em sua formação, porém público em sua ação.

Acredita-se que o questionamento em torno da abordagem clássica permite-nos visualizar o universo de discussão que permeia, hodiernamente, o estudo sobre o papel político-social do Terceiro Setor. Longe de esgotar a reflexão, possibilita-nos apreender as vicissitudes inerentes à construção de sua ação social, reconhecendo os avanços e retrocessos na construção de um referencial conceitual e de sua inserção nos espaços públicos.

Daí a importância de lançar elementos que possibilitem ao leitor um olhar mais reflexivo em torno da múltipla abordagem existente em torno desse ator social e identificar os caminhos norteadores desta reflexão. Eis a relevância de se considerar todo o universo de gênese do Terceiro Setor para que se apreendam os múltiplos olhares existentes.

Assim sendo, a reflexão desenvolvida no presente artigo insere-se em um debate maior que não se restringe apenas na tese de diminuição da ação social do Estado e do limite do

\footnotetext{
11. Destacando-se as obras de MONTAÑO, Carlos. 'Das "lógicas do Estado" às "lógicas da sociedade civil": Estado e “terceiro setor" em questão', e SARACHU, Gerardo. 'Ausencias y olvidos en el debate sobre el "tercer sector": algunas anotaciones para la reflexión del Sevicio Social', ambos publicados em março de 1999, na revista acadêmica Serviço Social \& Sociedade.
} 
mercado em viabilizar melhores condições de vida à população. Os argumentos apresentados contrapor-se-ão claramente à analise dos autores clássicos, como Rubem César Fernandes.

Todavia, torna-se importante reconhecer que, mesmo apresentando ausência de uma maior criticidade analítica, sobretudo em sua dimensão política, o estudo desenvolvido por Fernandes possibilita a sistematização de conhecimentos sobre a história político-social desse setor, dando destaque à articulação entre os diversos sujeitos que o compõem e identificando seus desafios e possibilidades.

\section{Terceiro Setor: de uma nova prática política à despolitização da questão social}

Depois de observado, ainda que sinteticamente, o percurso clássico de fundamentação do surgimento histórico do Terceiro Setor e de sua configuração na América Latina, apresentar-se-á um novo olhar sobre esse ator social.

Como dito anteriormente, reconhece-se a contribuição acadêmica da abordagem de Rubem César Fernandes, ${ }^{12}$ sobretudo por viabilizar um mapeamento das ações desenvolvidas pelo Terceiro Setor na América Latina, apresentandonos dados e um perfil do surgimento e da atuação das ONGs em nosso continente.

Entretanto, torna-se premente uma reflexão de cunho crítico, apresentando os meandros político-econômicos que interferem, igualmente, na configuração de um novo espaço público $\mathrm{e}$ de uma nova relação entre Estado e sociedade civil.

Por esse viés analítico, a expansão do Terceiro Setor encontra-se intimamente relacionada com o processo de reestruturação produtiva, o avanço dos pressupostos políticos do neoliberalismo e da globalização econômica, sobre os quais discorreremos brevemente.

Em outras palavras, a análise da emergência do Terceiro Setor e seu fortalecimento pode darse pela compreensão do processo de globalização econômica e ascensão da teoria neoliberal, os quais primam pelo fortalecimento do caráter subjetivo do mercado e a progressiva retirada do

12. Os estudos desenvolvidos por Leilah Landim são igualmente fundamentais na formação de um perfil das ONGs no Brasil.
Estado dos espaços públicos. ${ }^{13}$ Adentraremos, pois, em uma abordagem teórica mais crítica, sobretudo sobre o modo e o significado do surgimento do Terceiro Setor na América Latina.

Iniciamos uma nova compreensão do conceito de Terceiro Setor, aludindo às duas categorias analíticas de Montaño (1999), a saber: a 'lógica do Estado' e a 'lógica da sociedade civil'. Segundo o autor, a elucidação dessa dupla lógica conduz ao entendimento dos fundamentos políticos que permeiam o programa de privatização e reformas orçamentárias e da Previdência Social correntes na última década.

Assim sendo, torna-se imprescindível o entendimento do conceito de neoliberalismo e sua interface na modificação do papel político do Estado e na emergência do Terceiro Setor ${ }^{14}$ ao longo dos anos 90 .

O pensamento político neoliberal tem sua origem na década de 1940, do século passado. Apresenta-se como uma construção teóricopolítica de reação ao modelo de Estado intervencionista. ${ }^{15}$

13. Para uma melhor análise dos impactos da política neoliberal na articulação dos novos movimentos sociais, ver: TEIXEIRA, Francisco José Soares. Globalização, ideologia e luta de classes, publicado na Revista de Sociologia e Programa de Pós-Graduação em Sociologia - FCL-Unesp, $\mathrm{n}^{\circ}$ 12, São Paulo, 2002.

14. Alguns autores consideram a influência do Welfare State para a fundamentação das ONGs, visto que o Banco Mundial, juntamente com governos de países capitalistas desenvolvidos e outras organizações internacionais via nessas entidades uma alternativa política para as estratégias neoliberais. Seria uma tentativa de conquista de parceiros antiestatais, os quais promoveriam o desenvolvimento social em constante harmonia com o mercado, promovendo a passagem do "welfare State" ao "ONGs welfare". Para uma melhor análise, ver SOUZA, Herbet. As ONGs na década de 90: In: Desenvolvimento, cooperação internacional e as ONGs. 1991. [Mimeo]. Outro autor que vê na ação das ONGs um instrumento de manutenção da política neoliberal é o sociólogo americano James Petras. Ver: PETRAS, James. Alternativa neoliberal e alternativas para a América Latina. São Paulo: Xamã Editora, 1999.

15. O modelo de Estado intervencionista é resultado direto de um estudo desenvolvido pelo economista John Maynard Keynes (1883-1946), em sua mais importante obra, The general theory of employment, interest and money. Keynes analisou as possíveis causas da crise de 1929 no sistema capitalista e os caminhos que poderiam restabelecê-la. A solução encontrada por Keynes envolvia, diretamente, o governo. Caberia a ele a devida cobrança de impostos e a aquisição de empréstimos a serem investidos em um projeto político-social de pleno emprego. Em outras palavras, através da intervenção estatal, havia a possibilidade de recuperação dos postos de trabalhos pelos desempregados, a aquisição de direitos e a distribuição de renda, o que garantiria o aquecimento da economia e resolveria o problema da crise. 
Dentre seus principais teóricos, destacamse Friedrich Hayek, Milton Friedman, Karl Popper, Lionel Robbins, Michael Polanyi e Ludwig Von Mises. O primeiro autor ${ }^{16}$ tornouse referência após a publicação, em 1944, de sua principal obra, intitulada $O$ caminho da servidão.

A crítica central de Hayek destina-se ao modelo de gestão da política econômica empreendida pelo Estado intervencionista, o qual é considerado como sendo uma ameaça à liberdade econômica e, sobretudo, política. Em outras palavras, o autor considera que a intervenção estatal conduz a um totalitarismo político e a uma perda gradativa da liberdade do mercado. Daí defender a livre concorrência como princípio que rege a organização social. Segundo o autor:

A doutrina liberal é a favor do emprego mais efetivo das forças da concorrência como meio de coordenar os esforços humanos, e não de deixar as coisas como estão. Baseia-se na convicção de que, onde exista a concorrência efetiva, ela sempre se revelará a melhor maneira de orientar os esforços individuais. (Hayek, 1990,p. 58)

O ápice de consolidação de uma corrente teórica neoliberal dá-se em 1947, com a formação da Mont Pelérin Society, ${ }^{17}$ na Suíça. A associação internacional reunia, a cada dois anos, um seleto grupo de teóricos para pensar as diretrizes teórico-políticas de combate ao keynesianismo e a construção de um outro modelo de desenvolvimento do capitalismo favorável à livre iniciativa.

Pode-se dizer, pois, que esse encontro propiciou a sistematização da base conceitual de oposição ao modelo de Estado de bem-estar social e que inicia seu processo de consolidação ao final da década de 1970, com os governos de Margareth Thatcher, Ronald Reagan e Helmut Khol. ${ }^{18}$

Em seu bojo, o neoliberalismo prima por um processo de desestatização das indústrias nacio-

16. Friedrich August von Hayek nasceu em 1899, em Viena, e foi discípulo de Ludwig von Mises.

17. Sociedade de Mont Pèlerin, fundada por Hayek.

18. Representantes políticos da Inglaterra (1987), dos Estados Unidos (1980) e da Alemanha (1982), respectivamente. nais, desregulamentação, pelo Estado, das atividades sociais e econômicas e, por fim, perda dos direitos de proteção social, antes garantidos pelo Estado de bem-estar social. As conseqüências do projeto neoliberal podem ser vistas por, pelo menos, três vieses analíticos (Fernandes, 2000): 1. no campo social: crescente processo de exclusão social, agravado pela má distribuição de renda e pela segmentação social; 2 . no campo econômico: reestruturação do modo de produção da mercadoria, aumento do desemprego, criação de um exército de reserva não absorvido pelo mercado de trabalho e instabilidade nos padrões de crescimento econômico; 3 . no campo político: criação de regimes antidemocráticos, com uma constante desarticulação política dos sindicatos, impedimento da participação política plural e a adoção de medidas de restrição da democracia representativa, que resultam no desmonte dos principais mecanismos de defesa da soberania nacional.

Reside nessas medidas a importância de compreender os meandros político-sociais presentes na fundamentação teórica do neoliberalismo. A implementação do projeto neoliberal, sobretudo nos países latino-americanos, vem seguida de uma distorção do significado político do Estado, da sociedade civil e do mercado. Em outras palavras, há a separação entre os aspectos político, econômico e social que compõem o Estado e a sociedade civil. Conforme o pensamento de Montaño, almeja-se uma:

[...] 'des-economização’ das relações políticas e a 'des-politização' dos fenômenos tanto 'econômicos' quanto 'sociais'; com isto obtémse a 'des-historização' do real (o pretendido 'fim da história' de Fukuyama). (Montaño, 1999, p. 57)

Decorre daí uma visão que compartimentaliza a intervenção do Estado, da sociedade civil e do mercado no interior dos espaços públicos. O próprio fundamento político presente na proposta de reforma do Estado traz consigo toda essa lógica. Segundo Montaño, baseado em um discurso favorável à chamada 'parceria' com a sociedade civil, o projeto neoliberal prossegue no processo de "passagem das 'lógicas do Estado' para as 'lógicas da sociedade civil"” (Montaño, 1999, p. 57) 
A tentativa de estabelecer mecanismos de parceria, sobretudo com as ONGs, faz com que, pouco a pouco, o Estado se exima de seu papel como gestor das políticas públicas. A defesa da reforma política tende a funcionar como uma justificativa de 'enxugamento' da máquina burocrática, atendendo às prerrogativas neoliberais de redução da ação social do Estado.

Dentre as reformas previstas pelo Estado, encontra-se a progressiva diminuição dos investimentos em políticas públicas de caráter social. Observa-se uma inversão de prioridades, destacando a importância dada à política econômica em detrimento da esfera social, cujas necessidades passam a ser 'atendidas' por programas de caráter micro e pontuais, com o investimento de receitas cada vez menores.

Desse modo, há um redirecionamento da agenda social do Estado, que passa a priorizar um modelo político mais focalizado e desconcentrado politicamente, uma vez que desarticula o eixo político entre as instâncias federais, estaduais e municipais. O resultado direto da retirada do Estado da gestão das políticas públicas é o caráter precário existente nos programas sociais empreendidos pela administração pública, marcados por práticas assistenciais, emergenciais, distanciadas de uma reflexão concisa em torno da inclusão social.

E como a sociedade civil se insere nessa nova configuração política? Com a crise políticoeconômica presente nos países africanos e do Leste Europeu, na década de 1990, e o agravamento das disparidades sociais em países desenvolvidos, a cooperação internacional reduziu os recursos enviados para a manutenção de várias ONGs latino-americanas. Não tendo nenhuma política interna de sustentabilidade, as ONGs passam a ver no Estado uma forma de parceria e angariamento de recursos para a execução de seus projetos.

O mecanismo de colaboração entre ambos dá-se por meios operacionais e pontuais, através de convênios nos quais as ONGs tendem a ser contratadas para a realização de projetos específicos e com duração limitada de tempo.

Tal forma de inserção social espelha-se em um padrão de comportamento exigido pela própria lógica do capital, donde "en el campo de prestación de servicios serán las reglas de mercado las que orientarán la acción del sector, calidad de los sevicios, relaciones costo eficiencia-eficiencia, formación de recursos humanos, ateción al cliente, etc" (Sarachu, 1999, p. 137)

Embora o Estado reconheça a necessidade de parceria com tais organizações, sobretudo diante das grandes transformações surgidas e da exigência de inovações em sua forma de relacionamento, ainda existem restrições em face da forma de atuação de algumas ONGs no campo político.

Trazendo essa análise para a realidade brasileira, surge a hipótese de que os projetos desenvolvidos pelo Comunidade Solidária, durante a gestão do ex-presidente Fernando Henrique Cardoso, tiveram como meta principal a transferência de ações tidas como governamentais para a solidariedade das entidades sociais presentes na sociedade civil. ${ }^{19}$

Entretanto, a idealizadora do programa, a antropóloga Ruth Cardoso, reconhece nessa iniciativa novos padrões de relacionamento entre os setores governamental, privado e social. Segundo Sarachu, a coordenadora do programa:

[...] considera que el gobierno debe dedicarse a garantizar los derechos esenciales y universales de los ciudadanos, los que a su vez deben exigir que eso se haga de modo eficiente y equitativo, por lo que las organizaciones de la sociedad civil tienen su espacio. Pero lo que es proprio del 'tecer setor' siendo una caracteristica distintiva, es la construcción de nuevas formas de hacer en el área social. Las organizaciones de la sociedad civil ganaron una competencia en el modo de relacionarse con e intervenir junto a grupos sociales especificos, se coloca allí su contribución a las acciones integradas con el gobierno. (Sarachu, 1999, p. 138)

\footnotetext{
19. Sarachu faz referência ao Conselho do Comunidade Solidária. Em seu artigo, apresenta-o dentro da discussão que considera o Terceiro Setor como uma nova forma de intervenção no social. Ruth Cardoso, idealizadora do conselho, considera a existência de uma esfera pública não-estatal $\mathrm{e}$ de iniciativas privadas com sentido público, que permitem a interlocução entre a esfera governamental, o setor privado e a sociedade civil. Como espaço de interface entre os três setores, propicia a permanência e a universalidade das políticas (decorrentes da lógica do Estado) e uma forma inovadora de intervenção social por parte da sociedade civil.
} 
Consideramos a existência de estratégias desenvolvidas pelo Estado em sua aproximação com o Terceiro Setor que podem comprometer a integridade, a independência e a autonomia desses atores sociais, subordinando-os ao cumprimento de uma série de diretrizes preestabelecidas pelo próprio Estado, negando assim os princípios que deveriam orientar uma ação parceira.

Nesse sentido, recuperando a análise de Rubem César Fernandes, surge um 'Terceiro Setor', 'não-governamental' e 'não-lucrativo' (1994, p. 19) que passa a desempenhar funções de caráter público. E com ele emerge toda uma discussão acerca da construção de um espaço público não-estatal de assunção das atribuições do Estado em prol da redução da miséria e da pobreza.

Como exemplo, podemos citar o surgimento do discurso voltado para a responsabilidade social no Brasil, que ocorre concomitantemente ao momento político em que os empresários reivindicam a legitimação de sua ação social. E isto acontece na construção de um novo espaço público não-estatal, campo de disputa entre os diferentes atores sociais em busca de uma regulação do social.

No interior desse campo, uma questão torna-se fundamental: embora se apresentando como sujeitos propulsores do capital no interior das relações econômicas capitalistas, no momento em que participam das discussões sobre os rumos tomados pela política ou, ainda, investem em projetos sociais, os empresários inserem-se no chamado 'Terceiro Setor'. Passam, pois, a reivindicar, com os demais sujeitos que compõem esse segmento, um modelo de regulação social com melhores resultados que os obtidos por meio dos programas desenvolvidos pelo Estado.

Para autores que comungam com a abordagem de Fernandes, reside nesse aspecto a ampliação do Terceiro Setor, possibilitando, cada vez mais, a entrada de novos sujeitos, dentre eles o empresariado. ${ }^{20}$

20. Ver PAOLI, Maria Célia. Empresa e responsabilidade social: os enredamentos da cidadania no Brasil. In: SANTOS, Boaventura de (Org.). Democratizar a democracia: os caminhos da democracia participativa. Rio de Janeiro: Civilização Brasileira, 2002.
Baseando-se no discurso de redução do papel político-social do Estado, constroem um discurso de legitimação do espaço público nãoestatal, como locus de reflexão e atuação em prol da inclusão social, por meio do preenchimento do espaço antes ocupado pela administração pública estatal. Afirmam-se, portanto, como uma alternativa viável diante dos entraves burocráticos da máquina estatal, considerado como um dos grandes limites para o avanço na promoção da eqüidade social.

Vale destacar que o emprego da categoria 'não-estatal' constitui uma evidente transferência dos serviços sociais à sociedade civil. Representaria a formação de um terceiro segmento, denominado Terceiro Setor, que, ao lado da iniciativa privada e da instância governamental, seria responsável pelo fomento de ações de caráter solidário, filantrópico, assistencialista e voluntarista. ${ }^{21}$

Ora, comungando com o pensamento de Montaño (1999), contrapomo-nos justamente a essa justificativa que busca demarcar o surgimento do Terceiro Setor no momento de desmonte político do Estado. Reforçando essa afirmativa, Montaño ressalta que o projeto político neoliberal visa, principalmente, a:

[...] uma nova estratégia hegemônica do grande capital, de reestruturação produtiva, de reforma [...] do Estado, de globalização da produção e dos mercados, de financeirização do reinvestimento do capital, em face da atual crise de superprodução e superacumulação que envolve, dentre vários aspectos, um novo trato à 'questão social'. (Montaño, 1999, p. 61)

Como dito anteriormente, na nova demarcação conferida à questão social, a elaboração de políticas públicas torna-se gradativa e expressivamente focalizada, emergencial e, portanto, precária. Politicamente isto é um reflexo do redirecionamento das prioridades que passam a compor a agenda do Estado diante do projeto político neoliberal. E, economicamente, ocorre o paulatino esvaziamento dos cofres

\footnotetext{
21. Para uma reflexão maior, ver: PEREIRA, Luiz Carlos Bresser \& GRAU, Nuria Cunill (Orgs.). O público não-estatal na reforma do Estado. Rio de Janeiro: Editora Fundação Getúlio Vargas, 1999.
} 
públicos para o investimento em políticas de caráter social. ${ }^{22}$

O que observamos é que, sob a ótica neoliberal, os projetos sociais tornam-se submissos aos princípios de focalização que não contemplam o atendimento dos interesses universais dos cidadãos e tampouco se importam com a promoção de um espaço público verdadeiramente democrático e inclusivo.

O paulatino processo de reorientação da ação político-social do Estado, evidenciada, principalmente, nas reformas políticas e previdenciárias, acarreta conseqüências diretas para a própria sociedade, que passa a se responsabilizar pelo financiamento direto dos serviços outrora desenvolvidos pelo Estado.

Entretanto, uma ampla parcela da população encontra-se em situação de pobreza e/ou miséria absoluta, necessitando diretamente (e urgentemente) da aplicação das políticas sociais por parte do Estado. Nesse sentido, longe de contemplar a dimensão pública proposta por Keynes, o Estado diminuído planeja e executa uma série de programas com um caráter fortemente assistencialista, emergencial, negando a 'lógica democrática', de autonomização do cidadão.

Em outras palavras, há uma progressiva substituição de políticas públicas por programas sociais, os quais mantêm uma ação focalizada e descomprometida com qualquer perspectiva de transformação dos quadros de miséria social.

Ao negar a autonomia política ao cidadão, tolhe-se a oportunidade de construção de uma ação política verdadeiramente democrática. É interessante observar a reflexão desenvolvida pelo filósofo grego Cornelius Castoriadis, ao afirmar que:

A autonomia surge, como germe, assim que a interrogação explícita e ilimitada se manifesta, incidindo não sobre "fatos", mas sobre as significações imaginárias sociais ${ }^{23}$ e seu fundamento possível. [...] O momento do

$\overline{22 . \text { Consideremos }}$ como políticas sociais as que compreendem a saúde, a educação, a previdência social, o segurodesemprego, dentre outras ações que tornam-se metas secundárias diante das prioridades do grande capital.

23. Para Castoriadis (1992), as significações imaginárias constituem o eixo central de fundação e de compreensão da nascimento da democracia, e da política, não é o reinado da lei ou do direito, nem os dos "direitos dos homens", nem mesmo a igualdade dos homens como tal: mas o surgimento, no fazer efetivo do coletivo da coletividade, da discussão da lei. Que lei devemos fazer? Nesse momento nasce a política; em outras palavras, nasce a liberdade como social-historicamente efetiva. (Castoriadis, 1992, p. 139)

Com a luta pela participação nos processos decisórios, é garantida uma mobilização em busca de objetivos preconizados, os quais ocasionarão conseqüências extremamente importantes no cotidiano de cada um de nós. A ação de uma sociedade autônoma torna-se, portanto, "momento de criação, que inaugura não só outro tipo de sociedade, mas também outro tipo de indivíduos. Eu falo exatamente de germe, pois a autonomia, tanto social como individual, é um projeto" (Castoriadis, 1992, p. 139).

Portanto, a autonomia, como conceito atrelado à práxis, requer a elucidação do próprio significado assumido pela política. Torna-se uma conseqüência prática de autogestão, que se processa no interior das instituições e da sociedade em geral.

A ausência de uma valorização da condição humana por parte do Estado neoliberal conduz a um processo de privatização da questão social, transferindo-a para a sociedade civil, representada pelo segmento organizado e ativo, como os movimentos sociais e as ONGs e o Terceiro Setor. Como dito anteriormente, uma parcela do empresariado passa a ocupar, juntamente com a sociedade civil, o espaço de regulação da questão social.

Não é objetivo do presente artigo adentrar em uma análise do que se denomina responsabilidade social das empresas. Entretanto, é deveras importante situar a inserção do empresariado na configuração política que os espaços públicos adquirem, principalmente na década de 1990.

sociedade e de suas instituições, dando-lhes suporte valorativo. A não-compreensão dessa dimensão simbólica torna a análise social periférica e superficial. Além disto, o imaginário apresenta-se como instância de fundamentação das visões de mundo, dando significado à sociedade e à história. É o que alimenta a história da sociedade, reconstituindo-se cotidianamente. 
Ademais, a atual discussão em torno da atuação social dos empresários alavanca uma importante reflexão sobre o significado político da filantropia empresarial, uma vez que finda por assumir um caráter estratégico voltado à obtenção de uma visibilidade maior perante a sociedade - estrategicamente capitalizado como marketing comercial, com um investimento social mínimo e amparado em uma série de benefícios oriundos do Estado.

Portanto, a reestruturação da dimensão política e econômica do Estado proporciona uma nova abordagem para a questão social (Montaño; Sarachu, 1999), traduzida em duas respostas: a precarização das políticas sociais estatais e a privatização da seguridade e das demais políticas sociais.

$\mathrm{O}$ caráter privado conferido à questão social converge para uma dupla relação: o processo de remercantilização dos serviços sociais, agora tratados como mercadoria, no sentido marxista do termo. Os serviços tornamse, pois, um produto ofertado aos 'supostos' consumidores, reproduzindo, assim, a lógica marxista de reprodução da mais-valia do próprio trabalhador. Nos termos de Mota:

[...] na atual estratégia do capital, a reforma da previdência (diferenciando uma básica, estatal, e uma complementar, privada e mercantilizada) se constitui numa 'forma de apropriação de parte do salário do trabalhador' [...] que agora 'compra' tais serviços, criando uma nova área produtiva rentável e passando a ser o trabalhador, mais do que o Estado, a fonte de financiamento do capital na procura do superlucro. (Mota, apud Montaño, 1999, p. 230)

A análise da privatização dos serviços sociais também é desenvolvida por Sarachu. Todavia, o autor assinala a existência de uma diferenciação conceitual: primeiramente, o termo 'privado' reveste-se do sentido gramsciano, no qual o indivíduo integra-se às organizações de forma voluntária, isto é, atribuindo um ato 'privado' ao seu modo de inserção. O segundo sentido refere-se ao próprio processo de privatização dos serviços públicos, no qual os indivíduos passam a pagar pelo atendimento de necessidades, tais como, segurança, saúde, educação, previdência privada. ${ }^{24}$
Tomando como referencial teórico Kameyama (1998), Sarachu argumenta que o caráter privado dos serviços tem como finalidade "[...] devolverle a la sociedad civil las acciones que fueron usurpadas por el Estado todopoderoso y centralizador, a la vez que reconocer que el mercado no puede dar respuesta a los problemas de la equidad social".

Ainda referindo-se ao caráter privado dos serviços sociais, Montaño afirma a ocorrência do processo de refilantropização das respostas dadas à questão social, momento marcado pela inserção política da sociedade civil, que passa a responder pela exclusão social sofrida por uma ampla parcela da população. As práticas filantrópicas, assistenciais, caritativas, e mesmo alguns projetos desenvolvidos pelo empresariado, tornam-se os possíveis instrumentos que sanarão as principais problemáticas sociais.

Entretanto, a nosso ver, longe de resolver o problema da exclusão social, a refilantropização provoca uma despolitização da questão social, uma vez que acelera a cisão entre o econômico e o social, e intensifica a dissociação entre a política e o 'direito a ter direitos'.

A crítica a esse último aspecto torna-se crucial, sobretudo por se perceber, dentro do discurso neoliberal, a nítida substituição de uma luta pela legitimação de práticas cidadãs e aquisição de direitos por um discurso permeado pela lógica do humanitarismo e da filantropia.

Acreditamos ser importante uma inserção política maior do Terceiro Setor, reforçando o papel político da sociedade civil, não no sentido de assumir o papel do Estado, mas de reforçar sua dimensão pública, construindo conjuntamente um projeto político amplo, de garantia de direitos, de valorização da participação política igualitária e plural. Por esse viés analítico, cabe ao Terceiro Setor " [...] actuar en la conquista y garantía de los derechos y de la ciudadanía de los excluidos funcionando como abogado ante el Estado y las empresas" (Sarachu, 1999, p. 136)

A assunção de um papel pró-ativo na conquista e na manutenção de direitos, contrapondo-

24. Sarachu refere-se ao conceito de privatização dos serviços públicos, tomando como referencial teórico Kameyama (1998). 
se a uma concepção que reconhece o caráter 'bondoso' dessas instituições, ${ }^{25} \mathrm{o}$ Terceiro Setor, além de propiciar um reforço da sociedade civil, faria com que fosse:

[...] criado um espaço 'alternativo' de produção/consumo de bens e serviços, não mercantil, e seriam estimulados os laços de solidariedade local. [...] o 'terceiro setor' viria compensar os serviços sociais e assistenciais que, via privatização ou esvaziamento dos recursos, o Estado deixa de brindar, repondo as políticas sociais, agora na esfera da sociedade civil [...]. (Montaño, 1999, p. 66)

A análise ora desenvolvida pretende estabelecer uma crítica justamente a essa visão 'positiva' que se constrói entre vários intelectuais estudiosos da ação do Terceiro Setor, sobretudo na América Latina. Consideramos que o discurso segundo o qual o Terceiro Setor reforça a sociedade civil pode trazer, embutido em si, uma perspectiva conciliadora, de reforço do grande capital. ${ }^{26} \mathrm{O}$ caráter assumido pelo capitalismo faz com que se processe a formação de

[...] uma cultura política da crise, marcada pelo pensamento privatista e pela constituição do cidadão-consumidor; passando, os trabalhadores, a privilegiar as práticas sobre as necessidades imediatas (e individuais) em detrimento do embate em torno de projetos societais. (Montaño, apud Mota, 1999, p. 191)

Assim sendo, prevaleceria a 'lógica do mercado' (sociedade civil), perpassada pelo espírito da concorrência e da meritocracia, que rejeita o poder político do Estado, considerado paternalista, incompetente no trato das políticas públicas e, portanto, nocivo à sociedade em geral. Conforme Montaño, a rejeição do Estado pautase por duas justificativas:

1. a que considera o Estado um instrumento de classe;

25. Evelina Dagnino, em seu artigo intitulado "Sociedade civil, espaços públicos e a construção democrática no Brasil", publicado em 2002, desenvolve importante análise acerca da dualidade existente entre Estado e sociedade civil, tecendo uma crítica ao caráter 'bondoso' atribuído aos segmentos organizados da sociedade, em detrimento da importância política do Estado.

26. Visão compartilhada por Montaño (1999).
2. a que vê no Estado um instrumento de 'tirania da maioria'.

No primeiro caso, nega-se a dimensão ampliada do Estado, ${ }^{27}$ em sentido gramsciano, que atribui uma importância política à sociedade civil, reconhecendo seu papel na desenvoltura política do Estado. Na concepção do filósofo marxista italiano, cabem à sociedade civil momento da superestrutura - os meandros de articulação das classes subalternas para inserção nos espaços públicos por meio da 'guerra de posição'.

Significa dizer a consolidação de espaços de direção político-ideológica, pautada no consenso e na participação dos vários segmentos organizados da sociedade civil, no intuito de formar uma 'vontade coletiva nacional-popular', capaz de alavancar e articular os múltiplos anseios e necessidades nela contidos.

Ao contrário da abordagem gramsciana, observa-se nos discursos de legitimação da prática política do Terceiro Setor um distanciamento progressivo do Estado, justificado por sua possível incompetência no trato da questão social.

Passa-se a ver nas entidades que compõem o Terceiro Setor um único locus de luta pela ampliação de direitos civis e políticos, negando a importância política do Estado e seu papel imprescindível no fortalecimento dos espaços públicos e do diálogo com a sociedade civil. ${ }^{28}$

A justificativa seguinte, qual seja, a do Estado como instrumento de 'tirania da maioria', abre caminho para a argumentação de Hayek ao considerar o Estado de bem-estar social um entrave para a liberdade do indivíduo e a expansão do capital. Busca-se, portanto, eliminar o Estado Ampliado, mantenedor do espírito democrático e dos direitos sociais.

Por esse viés analítico, o Terceiro Setor apresenta um caráter alternativo, no sentido de ser diferente do Estado e contrapor-se ao modelo de gestão da iniciativa privada. Entretanto, sua

27. Para um estudo da concepção gramsciana de Estado Ampliado, destaca-se: BUCI-GLUCKSMANN, Christinne. Gramsci e o Estado. Rio de Janeiro: Paz e Terra, 1980.

28. Os fundamentos teóricos dessa concepção de sociedade civil podem ser visto na obra do pensador alemão Jürgen Habermas, particularmente na obra Teoria da ação comunicativa (1987). 
estrutura diferenciada não significa a viabilização de mudanças concretas nos espaços públicos, no sentido de romper com o modelo de sistema de produção instaurado, gerador do atual quadro de exclusão social. Citando Sarachu (1998), Montaño escreve:

[...] o caráter alternativo do qual se fala nas diferentes análises dos autores que trabalham a problemática da economia social e/ou do terceiro setor se põe geralmente num sentido de integração diferencial dentro da ordem capitalista. [...] sendo raras, por não falar inexistentes no debate, as propostas tendentes a superar o capitalismo. (Montaño, 1999, p. 69)

O percurso analítico desenvolvido até aqui nos conduz a considerar que a essência do Terceiro Setor encontra-se indiretamente vinculada à lógica do capital, do lucro privado e do próprio poder estatal. Longe de cumprir verdadeiramente o papel de construtor de laços de solidariedade local, afirmando seu caráter alternativo diante da ineficiência do Estado no desenvolvimento de políticas sociais, o Terceiro Setor torna-se prisioneiro do pensamento neoliberal, uma vez que traz para si a responsabilidade para com a questão social.

Além de fomentar o que Montaño denomina 'fenômeno de auto-responsabilização' (Montaño, 1999), o Terceiro Setor contribui com o processo de "des-responsabilização do Estado e do mercado e do esvaziamento da dimensão de 'conquista' e de 'direitos' das políticas sociais” (Montaño, 1999, p. 72).

\section{Considerações Finais}

Embora apresente importância na consecução de uma nova forma de ação política, a emergência do Terceiro Setor durante a década de 1990 depara-se com algumas ambigüidades que merecem uma especial análise.

Primeiramente, alguns autores consideram que sua ação viabiliza a gestão privada de financiamento público e um modelo de solidariedade de caráter hierarquizado e dotado de uma moral considerada extremamente 'bondosa'.
Os argumentos apresentados no presente artigo visam abrir caminho para uma reflexão em torno do risco da privatização dos serviços públicos, destacando o caráter ambíguo no trato da pobreza e da exclusão social.

Ademais, buscamos atentar para os aspectos políticos da relação entre Estado e Terceiro Setor, que podem mascarar uma situação de perda de autonomia e identidade, enfraquecendo o potencial político desse ator social.

No cenário político, onde ganham visibilidade projetos despolitizados, privatistas e esvaziados de uma reflexão crítica em torno da questão social, cabe ao Terceiro Setor atentar para o significado assumido por sua ação, reconhecendo seus limites e buscando estabelecer uma auto-análise crítica para a elaboração de uma proposta política mais concisa.

Urge, portanto, a necessidade de compreender que cada um tem um papel político-social a ser desempenhado, faltando apenas uma consciência política mais sensível, compreendendo a necessidade de promover, no sentido gramsciano, uma hegemonia civil. ${ }^{29}$ A prática dessa hegemonia encontra-se justamente na mudança de mentalidade dos indivíduos no momento em que eles conscientizam-se como

$\overline{29}^{29}$ Gramsci, no $3^{\circ}$ volume dos Cadernos do cárcere, nota 7, refere-se ao conceito de 'hegemonia civil' como um contraponto ao conceito de 'revolução permanente'. Este, surgido antes de 1848, na França, representava as experiências jacobinas de 1789 até a contra-revolução francesa, em 1815. É próprio de um período caracterizado por maior autonomia das economias nacionais diante do mercado mundial e uma visível desarticulação política: Estado pouco desenvolvido, inexistência de partidos políticos de massa, de sindicatos econômicos e maior autonomia da sociedade civil com relação ao aparelho de Estado e às Forças Armadas. A expansão colonial européia, após 1870, promoveu profundas mudanças na configuração política dos Estados e da sociedade civil. As relações sociopolíticas presentes no período anterior vão, paulatinamente, se transformando, superando o modelo de 'revolução permanente', e assumindo o caráter de 'hegemonia civil'. Conforme o autor (2002, p. 24), "Ocorre na arte política o que ocorre na arte militar: a guerra de movimento torna-se cada vez mais guerra de posição [...]. A estrutura maciça das democracias modernas, seja como organizações estatais, seja como conjunto de associações na vida civil, constitui para a arte política algo similar às 'trincheiras' e às fortificações permanentes da frente de combate da guerra de posição: faz com que seja apenas 'parcial' o elemento do movimento que antes constituía 'toda' a guerra". É aqui que o autor desenvolve, pela primeira vez, o conceito de sociedade civil, inserido no próprio conceito que se esboça sobre o Estado Ampliado. 
sujeitos partícipes ${ }^{30}$ das principais decisões políticas, econômicas e, principalmente, sociais. É descobrir-se como ator e transformador de sua própria história. É compreender, mesmo, um novo sentido de autonomia entendida como uma pretensão do homem de tornar-se agente da sua vida e da sua história, isto é, autonomia como subversão da ordem social estabelecida.

É reconhecer uma nova dimensão dada à sociedade civil, a qual passa a ser compreendida como espaço de articulação, organização e representação dos diferentes valores, ideologias, culturas e interesses dos grupos sociais. Aqui consolidam-se projetos hegemônicos, de fortalecimento dos espaços públicos, sobretudo nos diálogos empreendidos entre Estado e sociedade civil.

\footnotetext{
Abstract: Arrent literature presents the Third Sector under two distinct analytical views: 1 . it appears as a viable altemative to the state inefficiency in the treatment of the social matter; 2 . energes of the neoliberal political project, which primes for the emptying of the public dimension of the State. The present article is a result of a bibliographical study and aims to present some considerations on the sociopolitical construction of the Third Sector, being emphasized a critical reflection, based in the analysis of the arrent sociopolitical beoblings in last the three decades that exert direct influence in the configuration of this social actor. It is intended to be an academic discussion about this character, weaving a logic argumentation to think the political paper it plays in the sociopolitical context of Latin America.
}

Key-words: Third Sector; participation; social matter.

30. Castoriadis (1992, p. 138) concebe a política grega como a "primeira emergência histórica do projeto de autonomia coletiva e individual. Se quisermos ser livres devemos fazer nosso nomos. Se quisermos ser livres, ninguém deve dizer-nos o que pensar." Conforme a teoria desenvolvida pelo filósofo grego, os indivíduos têm, por obrigação, de estar conscientes dos próprios atos e das próprias afirmações; refutar toda e qualquer forma de hierarquias preliminares nas posições respectivas dos indivíduos e promover o questionamento das instituições, na medida em que dependem da atividade consciente e explícita da coletividade, pressupondo a igualdade de todos nas tessituras da democracia. Para tanto, torna-se necessário, pois, a transformação das instituições em instituições democráticas. Daí Castoriadis considerar a política como uma atividade refletida e lúcida, que conduz à instauração das instituições desejáveis, pautadas na democracia como regime de auto-instituição explícita de instituições sociais que dependem de uma atividade coletiva.

\section{Referências}

CASTORIADIS, Cornelius. As encruzilhadas do labirinto, III: o mundo fragmentado. Rio de Janeiro: Paze Terra, 1987-1992.

DAGNINO, Evelina. Sociedade civil, espaços públicos e a construção democrática no Brasil. In: DAGNINO, Evelina (Org.). Sociedade civil e espaços públicos no Brasil. São Paulo: Paz e Terra, 2002.

FERNANDES, Luís. Neoliberalismo e reestruturação capitalista. In: SADER, Emir; GENTILI, Pablo (Orgs). Pós-neoliberalismo: as políticas sociais e o Estado democrático. 5. ed. Rio de Janeiro: Paz e Terra, 2000.

FERNANDES, Rubem César. Privado porém público: o Terceiro Setor na América Latina. Rio de Janeiro: Relume-Dumará, 1994.

FILOMENO, Nilton Regis. Uma janela para aquém do mercado: o desafio em construir um modelo de gestão no $3^{\circ}$ setor. Disponível em: www.interpsic. com.br Acesso em: outubro, 1997.

GRAMSCI, Antonio. Cadernos do cárcere, v. 3., 3. ed. Rio de Janeiro: Civilização Brasileira, 2002.

HAYEK, Friedrich. $O$ caminho da servidão. 5. ed. Rio de Janeiro: Instituto Liberal, 1990.

LANDIN, Leilah. Sem fins lucrativos: as organizações não-governamentais no Brasil. Rio de Janeiro: Instituto de Estudos da Religião, 1988.

. Para além do mercado e do Estado? Filantropia e cidadania no Brasil. Rio de Janeiro: Iser, 1993.

MELO, Francisco Cartaxo. Terceiro Setor: um exercício de cidadania. Disponível em: www.fenead. org.br/neaf/Meli,\%20Francisco\%20C..htm

MONTAÑO, Carlos. Das "lógicas do Estado" às "lógicas da sociedade civil": Estado e "Terceiro Setor" em questão. Revista Serviço Social \& Debate - Espaço Público, Cidadania e Terceiro Setor. n. 59, Ano XX, março, 1999.

PAOLI, Maria Célia. Empresa e responsabilidade social: os enredamentos da cidadania no Brasil. In: SANTOS, Boaventura de (Org.). Democratizar a democracia: os caminhos da democracia participativa. Rio de Janeiro: Civilização Brasileira, 2002.

SALAMON, Lester. Estratégias para o fortalecimento do Terceiro Setor In: IOSCHPE, Evelyn et. al. $3^{\circ}$ Setor: desenvolvimento social sustentado. Rio de Janeiro: Paz e Terra, 2000.

SARACHU, Gerardo. Ausencias y olvidos em el debate sobre el "tercer sector": algunas anotaciones para la reflexión del Servicio Social. Revista Serviço Social \& Debate - Espaço Público, Cidadania e Terceiro Setor. n. 59, Ano XX, março, 1999. 
SEMERARO, Giovanni. Gramsci e a sociedade civil: cultura e educação para a democracia. Petrópolis (RJ): Vozes, 1999.

TORO, Bernardo. O papel do Terceiro Setor em sociedade de baixa renda. In: IOSCHPE, Evelyn et. al. $3^{\circ}$ Setor: desenvolvimento social sustentado. Rio de Janeiro: Paz e Terra, 2000. 